\title{
Patients' and caregivers' perspectives on factors that influence understanding of and adherence to hospital discharge instructions: a qualitative study
}

\author{
Karen Okrainec MD MSc, Shoshana Hahn-Goldberg PhD, Howard Abrams MD, \\ Chaim M. Bell MD PhD, Christine Soong MD MSc, Michelle Hart MD MScCH, Beverley Shea RN PhD, \\ Sandra Schmidt RN MEd, Amy Troup BASc, Lianne Jeffs RN PhD
}

\section{Abstract}

Background: Many patients have difficulty understanding and adhering to discharge instructions once home from hospital. We assessed patient and family caregiver perspectives on factors that influence understanding of and adherence to discharge instructions.

\begin{abstract}
Methods: We conducted a qualitative study using semistructured interviews of participants aged 18 years or more enrolled in a multicentre mixed-methods study who were discharged from 3 acute care hospitals across Ontario with a diagnosis of congestive heart failure, chronic obstructive pulmonary disease or pneumonia. Patients were recruited between March and November 2016 . We used directed content analysis to derive themes and subthemes.
\end{abstract}

Results: Twenty-seven participants (16 patients and 11 family members) described 5 themes that affected their understanding of and adherence to discharge instructions: 1) the role of caregivers, 2) relationships with inpatient and outpatient health care providers, 3) previous hospital stay, 4) barriers to accessing postdischarge care and 5) system-level processes. Subthemes highlighted the importance participants attributed to who provides the instructions, the development of resilience and advocacy through previous admissions, the benefits of addressing language and physical disability barriers, reviewing instructions in a unhurried manner, and ensuring that written instructions are meaningful and actionable.

Interpretation: Care transition interventions targeting improved communication are unlikely to improve understanding of and adherence to discharge instructions on their own. A patient-centred framework that promotes positive relationships with a patient's circle of care, reflects previous experiences with discharge, addresses equity barriers, and enhances strategies for patient and caregiver engagement at the time of discharge may optimize understanding and adherence once the patient is home.

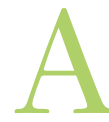

dverse events and unscheduled visits following discharge from hospital are common, avoidable and costly. ${ }^{1,2}$ High rates of adverse health outcomes have been attributed in part to discharge processes centred around poor communication and are thus a target of funding incentives and quality metrics across health care systems in Canada and the United States. ${ }^{3,4}$ Many transitional care interventions have therefore focused on optimizing communication at discharge through various patient-centred selfmanagement tools. ${ }^{5,6}$

Studies continue to show that, despite an improvement in patient communication, many patients have difficulty understanding and following discharge instructions. ${ }^{7}$ This is particularly of concern for patients with congestive heart failure, chronic obstructive pulmonary disease or pneumonia, for whom postdischarge adherence to medications, lifestyle modifications and follow-up may prevent unnecessary adverse events and unscheduled visits. ${ }^{8-10}$ These 3 diseases were identified during health reform in Ontario owing to their potential to increase cost efficiency through the standardization of care delivery, including at the time of discharge. ${ }^{11}$ Our objective was to identify factors that affect the ability of patients and their families to understand and adhere to their discharge instructions.

Competing interests: None declared.

This article has been peer reviewed.

Correspondence to: Karen Okrainec, Karen.okrainec@uhn.ca CMAJ Open 2019. DOI:10.9778/cmajo.20180208 


\section{Methods}

\section{Study design}

We conducted a qualitative study using inductive design with semistructured interviews.

\section{Participants}

We recruited patients between March and November 2016 who were enrolled in a double-blinded ongoing randomized controlled trial evaluating the influence of an additional discharge instruction tool compared to verbal patient instructions alone conducted at 3 acute care hospitals in Ontario (Toronto Western Hospital, Toronto General Hospital and Thunder Bay Regional Health Sciences Centre). ${ }^{12,13}$ Participants had an admission diagnosis of congestive heart failure, chronic obstructive pulmonary disease or pneumonia, 3 quality-based procedures that have at least 1 quality indicator focused on a transitional care need. ${ }^{11}$ Patients with cognitive impairment or language barriers could participate through the use of a professional interpreter or family member. Patients with a prognosis of less than 3 months or who were discharged to long-term care or another hospital were not eligible. Patients were informed about the principal investigator, study goals, and potential risks and benefits. All consecutive participants who were interested in the qualitative interview were contacted by the research team for consent, with enrolment stopping once thematic saturation had been met.

\section{Data collection}

We developed 2 sets of standardized semistructured openended interview guides, 1 for patients and 1 for family caregivers, to collect data based on a literature review and a pilot study $^{14}$ (Appendix 1, available at www.cmajopen.ca/content $/ 7 / 3$ / E478/suppl/DC1). Questions aimed to explore what factors affect the understanding and use of instructions. The 3 research assistants conducted one-on-one telephone interviews in English once within 1 week after discharge and remained blinded to the discharge intervention given to the participant by the health care team. The research team members who collected or analyzed data (K.O., S.H.-G. and L.J.) had no role in the patients' care. In addition to open responses during the interviews, descriptive information collected for the larger randomized controlled trial included 1) baseline demographic characteristics such as admission diagnosis, sex, age, presence of language barrier, limited health literacy, ${ }^{15}$ self-identified disabilities and reliance on caregivers (formal and family) for care and 2) 6 measures of patient experience collected by means of a standardized survey of self-reported understanding of discharge instructions. ${ }^{16}$

\section{Qualitative data analysis}

The core research team included a female clinician scientist in general internal medicine (K.O.), a female senior scientist with nursing background and experience in qualitative methods (L.J.), a female postdoctoral fellow in industrial engineering (S.H.-G.) and 3 female research analysts. The research analysts, who were trained by 3 coinvestigators (S.H.-G., L.J. and K.O.), conducted and transcribed verbatim the audiotaped interviews. Transcripts were analyzed by means of directed content analysis. ${ }^{17}$ The research analysts and principal investigator (K.O.) reviewed the transcripts line by line initially independently and then through consensus in face-toface meetings with all 5 core members. Initial codes (e.g., words and phrases) were identified and then collected into categories (e.g., interpretation of the codes). These categorical data were then further analyzed by all team members to identify key themes, which formed an initial coding schema. In additional to the manual coding, NVivo Pro software (QSR International) was used to identify key themes. ${ }^{18}$ Last, the themes from both the manual and NVivo coding were triangulated by the research staff and investigators. Methods of rigour included ensuring interrater reliability by cross comparison of the emergent themes for all team members at each iteration. Data saturation was met once no further themes were found. The team used selective coding within each theme identified to determine areas of focus.

\section{Ethics approval}

This study was approved by the institutional review board at the University Health Network, Thunder Bay Regional Health Sciences Centre, Baycrest Health Sciences Centre, Sinai Health System and Bruyère Continuing Care.

\section{Results}

Of the 144 participants enrolled in the randomized controlled trial, 27 (16 patients and 11 family caregivers) consented and were interviewed in this qualitative study. Interviews were conducted a mean of 18.9 days (standard deviation $29.6 \mathrm{~d}$, median $4 \mathrm{~d}$ ) after discharge and lasted 12-39 (average 23) minutes. Participants were mostly female, elderly, admitted for congestive heart failure and highly dependent on family for care, and reported moderate to low levels of understanding of discharge instructions after discharge (Table 1).

Our qualitative analysis identified 5 key themes that highlight important factors influencing understanding of and adherence to discharge instructions: 1) the role of caregivers, 2) relationships with health care providers, 3) previous experience as an inpatient, 4) accessibility barriers due to physical disability or language barriers and 5) system-level processes such as the benefits of having written instructions, a chosen time to review discharge instructions, presence of family and postdischarge follow-up (Table 2). The first theme (role of caregiver) was deemed to be large enough that subthemes could be explored; they are described in further detail elsewhere. ${ }^{19}$

\section{Individual-level themes}

\section{Relationship with health care providers}

Participants highlighted relationships with hospital and community providers, such as their pharmacist or primary care provider, as an important factor influencing adherence to follow-up care. Participants remembered the health care staff they engaged with while in hospital. Involving family members 


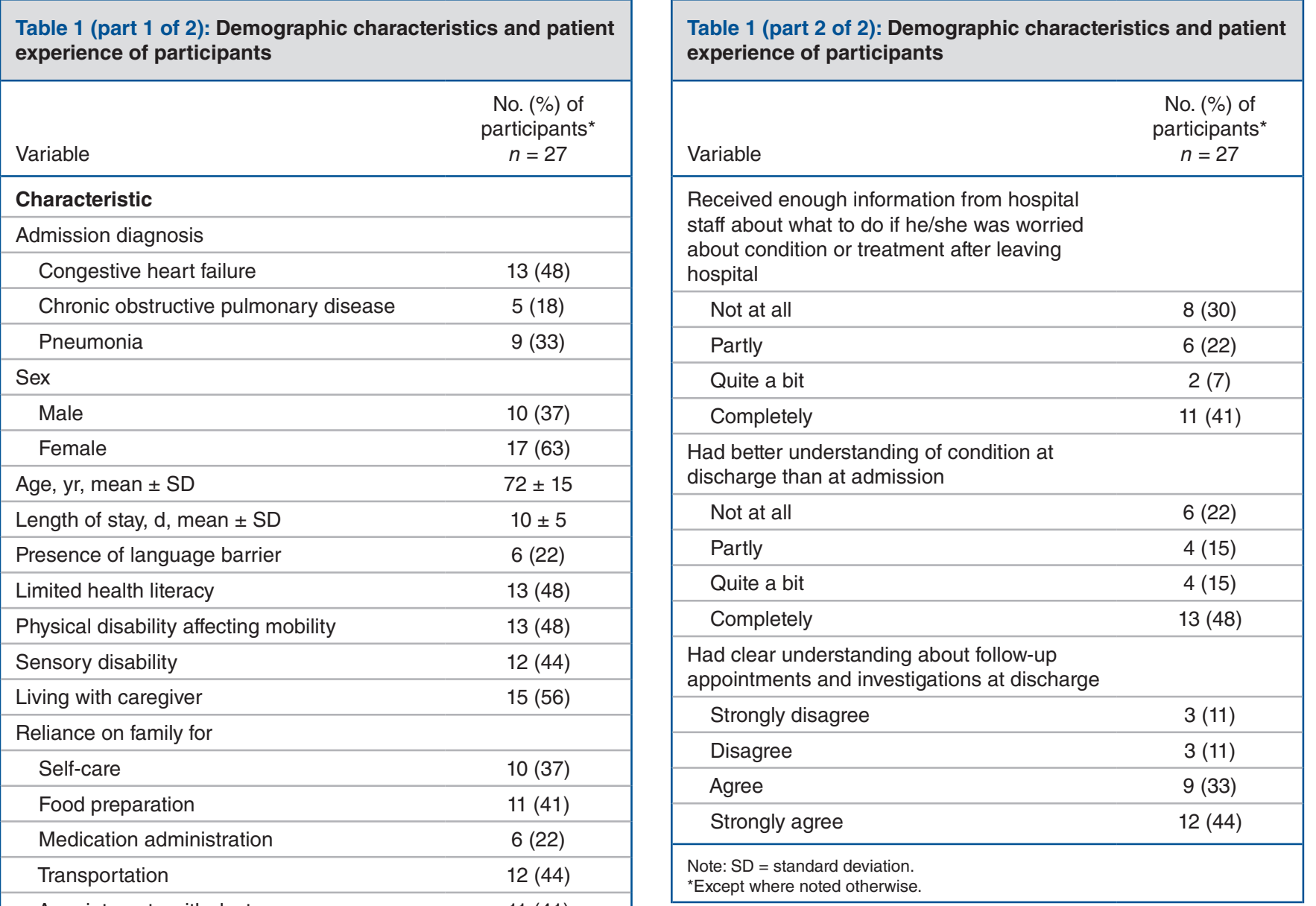

\begin{tabular}{|cc|}
\hline Appointments with doctors & $11(41)$ \\
\hline \multicolumn{2}{|c|}{ Receiving home support services } \\
\hline No. of days between discharge and interview \\
\hline$<3$ & $17(63)$ \\
\hline $3-7$ & $8(30)$ \\
\hline$>7$ & $10(37)$ \\
\hline Experience within 1 wk of discharge & $9(33)$ \\
\hline
\end{tabular}

Doctors, nurses or other hospital staff talked with patient about whether he/she would have the help needed when leaving hospital

\section{Received information in writing about what symptoms or health problems to look out for after leaving hospital}

Had clear understanding about all prescribed medications, including those he/she was taking before hospital stay, before leaving hospital

\begin{tabular}{|lc|}
\hline Not at all & $3(11)$ \\
\hline Partly & $5(18)$ \\
\hline Quite a bit & $7(26)$ \\
\hline Completely & $12(44)$ \\
\hline
\end{tabular}

when reviewing discharge instructions often changed the dynamic, such that participants felt connected to health care staff, more engaged when reviewing discharge instructions and interested in postdischarge follow-up. The relationship with hospital physicians was often contrasted to the relationship with the primary care provider. Some participants had had the same primary care provider for years and described a "family-like" bond. Others described a void in their postdischarge care and expected the care provided by the inpatient physician to extend into the postdischarge period. Last, some commented on the complexity of having multiple relationships with hospital physicians and how disjointed care can feel following discharge. Although most participants had a primary care provider, some expected the inpatient physician to "quarterback" postdischarge care, particularly when multiple specialists were involved.

\section{Lived experience}

Almost all participants identified a change after being in hospital, with "adaptation" being a necessary piece of the transition home. A participant with a previous hospital stay was more likely than a participant who had never been admitted to hospital before to reflect on subthemes of resiliency and selfsufficiency with all aspects of the discharge instructions. When a patient with congestive heart failure was asked whether she was given any instructions on diet restrictions, she answered, "No. I think they already know that I know [what I can't have]. ... I'm telling [the doctor] I can't have a banana" (participant 1030). 
Table 2: Representative quotes by key themes

\begin{tabular}{|c|c|}
\hline Theme & Quote \\
\hline \multicolumn{2}{|l|}{ Individual-level } \\
\hline $\begin{array}{l}\text { Relationship with health care } \\
\text { provider }\end{array}$ & $\begin{array}{l}\text { I can't say enough great things about him [inpatient physician]. He } \\
\text { listens and he really saw Mom as a person. And I'm relieved that we're } \\
\text { going to be seeing him next Tuesday. He told me to get all my questions } \\
\text { ready and write them down so I will be able to ask them again. } \\
\text { [Participant } 1016 \text {, family member] } \\
\text { I have to go see } 3 \text { more specialists just to follow up. But [the in-hospital } \\
\text { physician] is going to coordinate those specialists so nothing falls } \\
\text { through the cracks, like one prescribing } 1 \text { drug and then another, so } \\
\text { he's going to be the central person there. So it makes me feel safer. } \\
\text { [Participant } 1013, \text { patient] }\end{array}$ \\
\hline Lived experience & $\begin{array}{l}\text { I think that they realize this isn't our first rodeo. ... I think they realize that } \\
\text { we were both pretty up on it and ... didn't have to go into [resources to } \\
\text { assist with understanding condition discharge instructions] too much. } \\
\text { [Participant } 1025 \text {, family member] } \\
\text { Self-care is really important because our health care system is not what } \\
\text { it should be. [Participant } 5025 \text {, patient] }\end{array}$ \\
\hline Accessibility & $\begin{array}{l}\text { I can't walk. I'm tied to an oxygen tank. And I'm not able to use my } \\
\text { stairs. I have no one to help me. And I need to take an oxygen tank with } \\
\text { me, a wheelchair or a walker. But I need to have somebody take the } \\
\text { wheelchair down in order for me to go anywhere. So I don't go out of my } \\
\text { apartment. [Participant } 2005 \text {, patient] } \\
\text { My mom speaks a little bit of English ... she'll understand a little bit. But } \\
\text { if somebody [had] talked in Portuguese to her, it would have been a } \\
\text { different story ... they'd probably feel more comfortable. I was there } \\
\text { most of the time, and then my brother was there most of the time. We're } \\
\text { just taking part of everything.... I went through all her tests, I kind of } \\
\text { explain what is going on. [Participant } 5035, \text { family member] }\end{array}$ \\
\hline \multicolumn{2}{|l|}{ System-level } \\
\hline Utility of written instructions & $\begin{array}{l}\text { That would have been nice if they could do that [provide discharge } \\
\text { information a bit earlier] and just have any last-minute instruction on a } \\
\text { separate piece of paper and a summary and the main discharge papers } \\
\text { the day before. Because then I could read it all over and ask questions } \\
\text { right while I was there. [Participant 1016, patient] }\end{array}$ \\
\hline Feeling rushed & They just let you go. Goodbye. You're gone. [Participant 5025, patient] \\
\hline $\begin{array}{l}\text { Meaningful and actionable } \\
\text { content }\end{array}$ & $\begin{array}{l}\text { I sort of panicked there for a bit because I wasn't sure what I should do } \\
\text { if [my husband] went into atrial fibrillation. So, no, I think maybe we } \\
\text { could have been told a little more ... "If it happened, here's what you do." } \\
\text { [Participant 1027, family member] }\end{array}$ \\
\hline Role of follow-up & $\begin{array}{l}\text { We've got a lot of stuff to look over ... and process. And this is the first } \\
\text { time actually that we've come out and had a second chance to go back } \\
\text { and see the doctors and talk it over with them and ask again what } \\
\text { questions we have. You need a bit of time like this, and this is great. } \\
\text { This follow-up appointment is a big plus. I don't know if we would be } \\
\text { able to get an appointment with my family doctor to get in and get Mom } \\
\text { checked. [Participant 1016, patient] }\end{array}$ \\
\hline
\end{tabular}

\section{Accessibility and communication barriers}

The theme of accessibility, particularly with respect to physical disability and language barriers, was commonly described by participants as affecting their ability to follow through with instructions. Participants found it difficult to attend follow-up appointments because of physical limitations, lack of proximity to the appointment or resources to get there. Although the participating hospitals had access to professional interpreters, they were rarely used when discharge instructions were reviewed. Families described being with the patient consistently to pro- vide interpretation and did not think it was necessary to have an interpreter if they were present. All patients with language barriers stressed the role their families played in their understanding and following of discharge instructions. Families who acted as informal interpreters were often the ones to emphasize the importance of taking new medications, following diet recommendations and attending follow-up appointments. For patients who were discharged without scheduled appointments, in many cases it was the responsibility of the English-speaking family member to make the appointments. 


\section{System-level themes}

The need to improve the delivery of discharge instructions was a common theme identified, with subthemes including feeling rushed at discharge, preferring meaningful and actionable written instructions, benefits of including family when reviewing discharge instructions and the importance of postdischarge follow-up.

Many patients and their families expressed feeling pressured to give up their hospital bed before having reviewed discharge instructions. Participants stressed the importance of having instructions in writing to refer to after discharge. Content highlighted as most important centred around medications, signs and symptoms to watch for and home care support. Participants shared not feeling ready for what was to come and highlighted the need for actionable content such as knowing what to expect and what level of support would be needed once home. Patients who reported understanding their instructions also reported adhering to their instructions, and these concepts were often interconnected in phrases such as "I read them and follow them to the letter. And I make sure I understand" (participant 1013). Engagement was highlighted as "going the extra mile" and was often synonymous with education; 1 patient stated, "They treat you, but they don't teach you" (participant 1029). Family reported frustration when not present at discharge even if instructions were written. Participants who self-identified as caregivers highlighted the need to involve family. This distinction is important, as care from family extended across the spectrum of care and included relevant tasks linked to adherence such as picking up medications or equipment. Participants described follow-up care after discharge as pivotal for reviewing instructions not understood at the time of discharge or for asking questions that emerged after discharge.

\section{Interpretation}

We identified 5 core themes from patients and family caregivers that highlight opportunities for improving understanding of and adherence to hospital discharge instructions. Participants described themselves as being centred among a larger network of relationships, from the in-hospital staff who provided instructions and quarterbacked care to the primary care physician or community pharmacist who reviewed instructions after discharge. Participants then characterized the lens in which a prior lived experience with hospital discharge can provide adaptation tools to facilitate follow-through with instructions when needed. The next theme reflected persistent yet unaddressed barriers due to language or physical disability. The last theme reflected process factors related to the delivery of patient instructions. Together, these themes highlight factors that, when addressed at discharge, may optimize understanding of and adherence to instructions once the patient is home.

Our findings lend insight on patient-level factors that enable a successful transition home for any health care institution or provider who provides discharge instructions. Studies have documented the complex but indispensable role informal caregivers play in care coordination and highlight how family presence when reviewing discharge instructions can help reinforce, clarify and improve adherence. ${ }^{19,20}$ The importance that perceived relationships with health care providers may play in the patient's level of engagement and adherence to instructions has previously been described as important for adherence to medications. ${ }^{21}$ This factor is of timely importance given recent work showing that both inpatient and outpatient physicians rarely feel responsible for patient care and adherence after discharge. ${ }^{22,23}$ Providers who feel a sense of responsibility are more likely to spend the necessary time at discharge to optimize the transition from hospital to home. Our results highlight a missed opportunity to address patients' existing relationships with their circle of care and suggest that the best health care provider to follow up on discharge instructions may be the one the patient has the closest perceived relationship with. Our findings suggest that communication needs surrounding discharge among patients and families who have prior hospital experience may differ from those who do not. This theme is in line with the findings of Krumholz, ${ }^{24}$ who coined the term "posthospital syndrome," and suggests potential areas of improvement for care transition interventions. Our study highlights an opportunity for health care providers to inquire about difficulties in adhering to the discharge plan owing to accessibility and language barriers to better identify the need for additional support before discharge. ${ }^{25}$ Like Karliner and colleagues, ${ }^{26}$ we found that, even when professional interpreters are available, families often aid with communication and adherence to postdischarge instructions.

Although patient communication is often a key factor in high-quality transitions, time spent on communicating discharge instructions has been found to be low relative to other discharge-relevant tasks..$^{27}$ Cawthon and colleagues ${ }^{28}$ noted that higher levels of patient engagement at the time of discharge are associated with higher rates of medication adherence and decreased readmission rates. However, the necessary system-level elements for optimal patient engagement at the time of discharge are rarely highlighted in care transition initiatives, which makes these factors difficult to reproduce or study. ${ }^{5}$

\section{Limitations}

Our participants reported low levels of understanding of the discharge plan, and it is possible that responses may have differed among younger participants with higher levels of health literacy. Most of our participants had a primary care provider, and the themes identified, such as the relationship with existing health care providers, may not be generalizable to patients without a primary care provider. Caregivers represented just under half of our participants and may have biased the responses to those most likely experienced by caregivers rather than patients. Also, our participants were part of a larger randomized trial, and some may have received a patient instruction tool; this may have influenced themes identified as system-level opportunities. Saturation was achieved with the sample size; however, further quantitative analysis among a larger cohort of patients could confirm how factors identified in our study influence adherence to instructions and outcomes after discharge. 


\section{Conclusion}

We identified individual- and system-level factors that highlight opportunities for improving patient understanding of and adherence to hospital discharge instructions through improved patient engagement and patient-centred communication at the time of discharge. These factors should be explored further when implementing and evaluating interventions meant to improve patients' understanding of and adherence to discharge instructions.

\section{References}

1. Forster AJ, Clark HD, Menard A, et al. Adverse events among medical patients after discharge from hospital. CMA7 2004;170:345-9.

2. Jencks SF, Williams MV, Coleman EA. Rehospitalizations among patients in the Medicare fee-for-service program. N Engl 7 Med 2009;360:1418-28.

3. Centers for Medicare \& Medicaid Services (CMS), HHS. Medicare program; hospital inpatient value-based purchasing program. Final rule. Fed Regist 2011; 76:26490-547.

4. Lapointe-Shaw L, Mamdani M, Luo J, et al. Effectiveness of a financial incentive to physicians for timely follow-up after hospital discharge: a populationbased time series analysis. CMA7 2017;189:E1224-9.

5. Okrainec K, Lau D, Abrams $\mathrm{H}$, et al. Impact of patient-centered discharge tools: a systematic review. 7 Hosp Med 2017;12:110-7.

6. Hansen LO, Young RS, Hinami K, et al. Interventions to reduce 30-day rehospitalization: a systematic review. Ann Intern Med 2011;155:520-8.

7. Cancino RS, Manasseh C, Kwong L, et al. Project RED impacts patient experience. 7 Patient Exp 2017;4:185-90.

8. Albrecht JS, Gruber-Baldini AL, Hirshon JM, et al. Hospital discharge instructions: comprehension and compliance among older adults. 7 Gen Intern Med 2014;29:1491-8.

9. Takeda A, Taylor SJ, Taylor RS, et al. Clinical service organisation for heart failure. Cochrane Database Syst Rev 2012;(9):CD002752.

10. Health Quality Ontario; Ministry of Health and Long-Term Care. Qualitybased procedures: clinical handbook for community-acquired pneumonia. Toronto: Health Quality Ontario; 2014. Available: www.hqontario.ca/evidence/ evidence-process/episodes-of-care\#community-acquired-pneumonia (accessed 2019 May 1).

11. Health system funding reform: quality-based procedures. Toronto: Ontario Ministry of Health and Long-Term Care; updated 2018 Oct. 10. Available: http://www.health.gov.on.ca/en/pro/programs/ecfa/funding/hs_funding_qbp.aspx (accessed 2018 Oct. 15).

12. Okrainec K. Patient oriented discharge summary impact study (PODS). ClinicalTrials.gov: NCT02673892. Available: https://clinicaltrials.gov/ct2/ show/NCT02673892 (accessed 2016 Feb. 4).

13. Hahn-Goldberg S, Okrainec K, Huynh T, et al. Co-creating patient-oriented discharge instructions with patients, caregivers, and healthcare providers. 7 Hosp Med 2015;10:804-7.

14. Hahn-Goldberg S, Okrainec K, Damba C, et al. Implementing patientoriented discharge summaries (PODS): a multisite pilot across early adopter hospitals. Healthc Q 2016;19:42-8.

15. Powers BJ, Trinh JV, Bosworth HB. Can this patient read and understand written health information? 7AMA 2010;304:76-84.

16. Canadian Patient Experiences Survey - Inpatient Care Survey instructions. Ottawa: Canadian Institute for Health Information; 2014. Available: https:// www.cihi.ca/sites/default/files/document/patient_expsurvey_inpatient_en.pdf (accessed 2019 July 9).

17. Hsieh HF, Shannon SE. Three approaches to qualitative content analysis. Qual Health Res 2005;15:1277-88.

18. Basit T. Manual or electronic? The role of coding in qualitative analysis. 7 Educ Res 2003;45:143-54.

19. Hahn-Goldberg S, Jeffs L, Troup A, et al. "We are doing it together"; the integral role of caregivers in a patients' transition home from the medicine unit. PLoS One 2018;13:e0197831.
20. Backman C, Cho-Young D. Engaging patients and informal caregivers to improve safety and facilitate person- and family-centered care during transitions from hospital to home - a qualitative descriptive study. Patient Prefer Adberence 2019;13:617-26.

21. van der Laan DM, Elders PJM, Boons CCLM, et al. Factors associated with antihypertension medication non-adherence: a systematic review. 7 Hum Hypertens 2017;31:687-94.

22. Young E, Stickrath C, McNulty MC, et al. Internal medicine residents' perceived responsibility for patients at hospital discharge: a national survey. 7 Gen Intern Med 2016;31:1490-5.

23. Jones CD, Vu MB, O'Donnell CM, et al. A failure to communicate: a qualitative exploration of care coordination between hospitalists and primary care providers around patient hospitalizations. 7 Gen Intern Med 2015;30:417-24

24. Krumholz HM. Post-hospital syndrome: an acquired, transient condition of generalized risk. N Engl 7 Med 2013;368:100-2.

25. Schoenthaler A, Knaful GJ, Fiscella K, et al. Addressing the social needs of hypertensive patients: the role of patient-provider communication as a predictor of medication adherence. Circ Cardiovasc Qual Outcomes 2017;10:e003659.

26. Karliner LS, Auerbach A, Nápoles A, et al. Language barriers and understanding of hospital discharge instructions. Med Care 2012;50:283-9.

27. Sharma A, Lo V, Lapointe-Shaw L, et al. A time-motion study of residents and medical students performing patient discharges from general internal medicine wards: a disjointed, interrupted process. Intern Emerg Med 2017;12:789-98.

28. Cawthon C, Walia S, Osborn CY, et al. Improving care transitions: the patient perspective. 7 Health Commun 2012;17(Suppl 3):312-24.

Affiliations: Open Lab (Okrainec, Hahn-Goldberg, Abrams, Troup), University Health Network; Division of General Internal Medicine (Okrainec, Abrams), University Health Network; Department of Medicine (Okrainec, Abrams, Bell, Soong) and Institute for Health Policy, Management and Evaluation (Soong), University of Toronto; Division of General Internal Medicine (Bell, Soong), Mount Sinai Hospital; Department of Family and Community Medicine (Hart), Baycrest Health Sciences, Toronto, Ont.; Bruyère Research Institute (Shea) and Ottawa Hospital Research Institute (Shea); School of Epidemiology and Public Health (Shea), University of Ottawa; Bruyère Continuing Care (Schmidt), Ottawa, Ont.; Li Ka Shing Knowledge Institute (Jeffs), St. Michael's Hospital, Toronto, Ont.

Contributors: Howard Abrams, Chaim Bell, Christine Soong, Michelle Hart, Beverley Shea, Sandra Schmidt, Amy Troup and Lianne Jeffs designed the study. Shoshana Hahn-Goldberg, Amy Troup, Lianne Jeffs and Karen Okrainec analyzed and interpreted the data. Karen Okrainec drafted the manuscript. All of the authors contributed to the study conception, critically revised the manuscript for important intellectual content, approved the version to be published and agreed to be accountable for all aspects of the work.

Funding: The Donald J. Mathews Fund from the Toronto General Hospital Foundation and the Mount Sinai Hospital and University Health Network Academic Medical Organization Innovation Fund provided financial support for this work.

Acknowledgements: The authors acknowledge all of the individual site leads and team members who participated in this study through participant screening, and consent and data collection: Parviz Masoudi, Jhiffee Locquiao, Agnes Kulinek, Rasha Kubba and Melanie Henry. They also thank the team members from other participating sites who contributed to the overall operations of the study, including Sharon Fiorelli, Nataly Vilgan, Aysha Rankin and Cheryl Ethier.

Disclaimer: The funding groups had no role in the design, conduct or implementation of the study or manuscript.

Supplemental information: For reviewer comments and the original submission of this manuscript, please see www.cmajopen.ca/content/7/3/ E478/suppl/DC1. 